\title{
Nasopharyngeal carcinoma, an analysis of histological subtypes and their association with EBV, a study of 100 cases of Pakistani population
}

\author{
Beena Umar', Rashida Ahmed ${ }^{1}$ \\ ${ }^{1}$ Department of Pathology and Microbiology, Aga Khan University, Karachi, Pakistan
}

\section{A B S T R A C T}

Introduction: Nasopharyngeal carcinoma is the most common nasopharyngeal malignancy. In recent decades, it has attracted world-wide attention because of complex interactions of genetic, viral, environmental and dietary risk factors, with an etiological association with the malignancy. Nasopharyngeal carcinoma (NPC) is a rare cancer throughout the world, with the exception of Southeast Asia, Southern China and North Africa. The Epstein-Barr virus (EBV) was discovered 38 years ago by electron microscopy of cells cultured from Burkitt's lymphoma tissue by Epstein, Achong, and Barr. EBV infection is a common infection in Pakistan due to poor socioeconomic conditions but its association with Nasopharyngeal Carcinoma is yet to be firmly established in Pakistani population and there is scarce local data available. Methods: A total of 100 consecutive cases of Nasopharyngeal Carcinoma, over a period of three years (2009-2011) were retrieved and reviewed from the pathology files at the Section of Histopathology, Aga khan University Hospital. Morphological sub classification of Nasopharyngeal carcinoma was done according to WHO. For the detection of EBV, LMP1 immunostain was used. Results: Among total of 100 cases, the male to female ratio was $3: 1$, with an age range of $13-78$ yrs and an average age of 42 yrs. Similar to other regions of world, Non-keratinizing Carcinoma (92\%) is the commonest sub-type with a distinct bimodal age distribution, followed by Keratinizing Squamous Cell Carcinoma (8\%) but there were no cases of Basaloid Squamous Cell Cacinoma. EBV-LMP 1 staining was demonstrated in 75/92 cases $(81 \%)$, while all cases of Keratinizing Squamous Cell Carcinoma were negative for EBV-LMP 1 staining. Conclusion: Prognostic impact of LMP-1 on Nasopharyngeal carcinoma is still unclear and also there are controversial studies regarding the prognostic effect of EBV on chemotherapy and radiotherapy, it is paramount that EBV positive and EBV negative patients be investigated for response to therapy to establish the importance of EBV association in nasopharyngeal carcinoma patients. The association with EBV is also very important because with ongoing research in the etiological basis of the tumors (associated with EBV) patients may also benefit from emerging immunotherapy used in these tumors.

Key words: Nasopharyngeal carcinoma, Keratinizing and non-keratinizing squamous cell carcinoma, Epstein barr virus, Latent membrane Protein-1

\section{INTRODUCTION}

Nasopharyngeal Carcinoma is the most common neoplasm of the nasopharynx irrespective of the geographyand race. Itdiffers from other cancers of the head and neck in its occurrence, unique etiological associations, clinical behavior and treatment. ${ }^{1}$ Though a rare cancer throughout the world but a leading form of cancer in Southeast Asia including the Southern China and Hong Kong, the Arctic, North Africa and the Middle East. ${ }^{2}$ In World Health Organization (WHO) classifications, 1991, three histological subtypes have been described, Keratinizing Squamous Cell Carcinoma (SCC), Non-keratinizing Carcinoma (further subdivided into differentiated and undifferentiated 
subtypes) and Basaloid Squamous Cell Carcinoma., In recent decades, it has attracted world-wide attention because of complex interactions of genetic, viral, environmental and dietary risk factors, with an etiological association with the malignancy. NPC is a unique model of human malignancywith a multi-step carcinogenic process involving a virus (Epstein Barr virus), environmental carcinogens, and an NPC susceptibility gene. ${ }^{2}$ The Epstein-Barr virus (EBV) belongs to Herpes Virus family and was discovered 38 years ago byelectron microscopy of cells cultured from Burkitt's lymphomatissue by Epstein, Achong, and Barr. Six years later, in 1970, EBV DNA was detected in tissues from patients with nasopharyngealcarcinoma. ${ }^{5} \mathrm{EBV}$ was the first human virus to be directly implicated in carcinogenesis. Most of the EBV infections result in latency, a small proportion of the people develops serious sequelae. During acute infection, EBV primarily infects and replicates in the stratified squamous epithelium of the nasopharynx. This is followed by a latent infection of B lymphocytes. ${ }^{6}$ As there is ubiquity of EBV infection worldwide but on the other hand, there is distinct geographic distribution of NPC, explaining the possibility that both environmental (such as dietary nitrosamines, occupational exposures to wood and formaldehyde, cigarette smoking) and host genetic factors (cytochrome P450 2E1 [CYP2E1] gene polymorphisms and polymorphisms in the HLA genes) also play a role in its pathogenesis. ${ }^{7} \mathrm{NPC}$ is often difficult to diagnose because of the non-specific nature of its clinical symptoms and the difficulty in visualizing the nasopharynx due to its relative inaccessibility. Most of the tumors remain undiagnosed until they present as metastasis to the cervical lymph nodes, often without overt pathology at the primary site. ${ }^{8}$

\section{MATERIAL AND METHODS}

A total of 100 consecutive cases of Nasopharyngeal Carcinoma, over a period of three years (2009-2011) were retrieved and reviewed from the pathology files at the Section of Histopathology, Aga khan University Hospital. Specimens not received in 10\% buffered formalin and cases with incomplete clinical data were excluded from the study. Diagnosis of Keratinizing Squamous Cell Carcinoma was given in cases showing squamous differentiation at the light microscopic level, in the form of intercellular bridges and/or keratinization over most of the tumour and is also morphologically similar to keratinizing squamous cell carcinoma as occurring in other head and neck mucosal sites. Cases of Non-keratinizing carcinoma showed solid sheets of cells, irregular islands, dyscohesive sheets and trabeculae of carcinoma intimately mixed with variable numbers of lymphocytes and plasma cells. Sub classification into the undifferentiated and differentiated subtypes was not carried out, since their distinction is not of much clinical or prognostic significance. For each case one representative section was selected and immunohistochemical stain (cytokeratin AE1/AE3) was performed (only in cases of poorly differentiated carcinomas). For the detection of EBV, LMP1 (DAKO, Denmark) immunohistochemical was used. Membranous and cytoplasmic staining was regarded as positive for both these immunohistochemical stains. Immunohistochemical staining was performed on deparaffinized tissue sections of formalin-fixed material after microwave-enhanced epitope retrieval. Detection was done with streptavidin-biotinylated-peroxidaseconjugated reagents, with 3- amino-9-ethyl carbazole as the chromogen and hematoxylin for counterstain.

Data was analyzed using SPSS version 19. Mean and standard deviation were computed for qualitative variables like age. Frequencies and percentages were calculated for categorical variables like gender, site, and subtypes of Nasopharyngeal Carcinoma. Chi-square test was used to check the association between EBV and subtypes of Nasopharyngeal carcinoma. The $\mathrm{p}$ value of $<0.05$ was considered as the level of significance.

\section{RESULTS}

Age and gender

The range of patient's age was 13 to 78 years with an average age of 42 years and standard deviation of +/19. There were 73 males and 27 females with male to female ratio of $3: 1$ (Table 1). Age range of male patients is 17-78 yrs with an average age of $44 \mathrm{yrs}$ and standard deviation of $+/-19$. Age range of female patients is 13-63 yrs with an average age of $36 \mathrm{yrs}$ and standard deviation of $+/-16$.

\section{Site}

Data on the sites involved (primary/metastatic) was also available for all 100 cases (Figure $1 \& 2$ ). In only 55 patients the tumor was limited to the primary site, rest of the 45 cases initially presented with metastases. The commonest site of metastases was the cervical lymph node (41 cases), followed by submandibular lymph node (1 case), maxilla (1 case) cavernous sinus ( 1 case) and metastases to the base of skull (1 case).

\begin{tabular}{lcc}
\multicolumn{3}{l}{$\begin{array}{l}\text { Table 1: Gender distribution of patients with } \\
\text { nasopharyngeal carcinoma }\end{array}$} \\
\hline Gender & $\begin{array}{c}\text { Non-keratinizing } \\
\text { carcinoma }\end{array}$ & $\begin{array}{c}\text { Keratinizing squamous } \\
\text { cell carcinoma }\end{array}$ \\
\hline Males & 66 & 7 \\
Females & 26 & 1 \\
Total & 92 & 8 \\
\hline
\end{tabular}




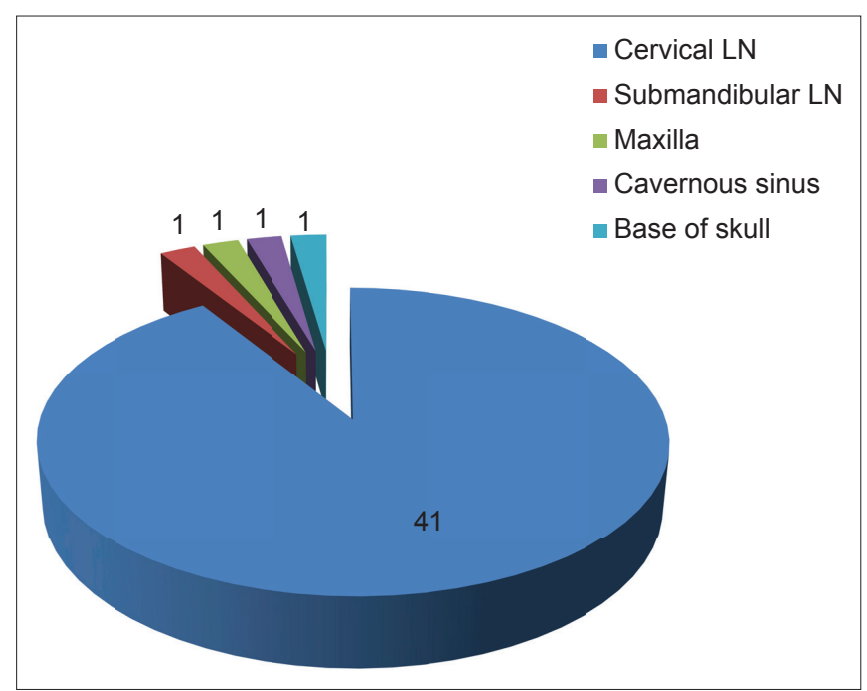

Figure 1: Involvement of metastatic sites in nasopharyngeal carcinoma

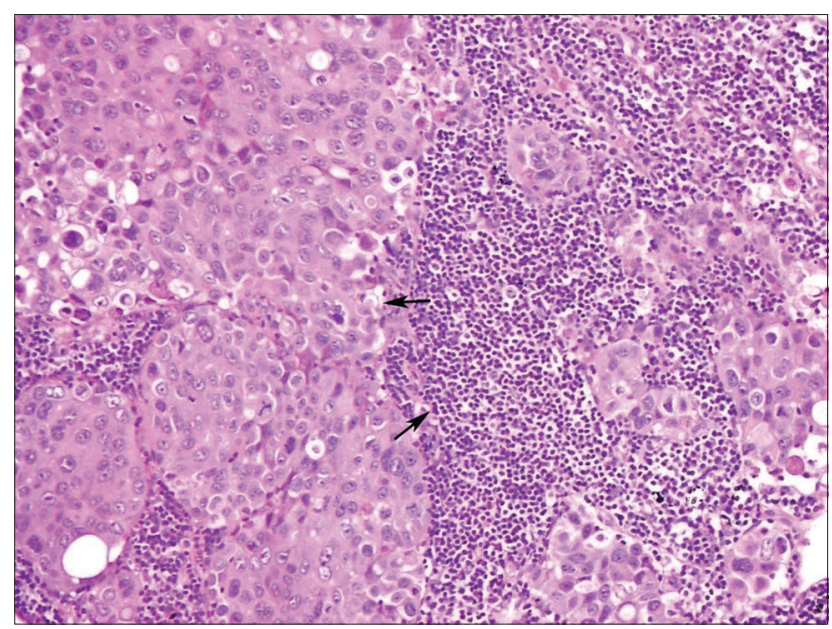

Figure 2: Cervical lymph node $\nearrow$ showing involvement by metastatic nasopharyngeal carcinoma $\leftarrow(20 \mathrm{X})$

\section{Histopathological classification}

Non-keratinizing Nasopharyngeal carcinoma was the most common subtype $92 \%$ (92 cases) followed by Keratinizing squamous cell carcinoma 8\% (8 cases)(Figure $3 \& 4)$. There were no cases of Basaloid Squamous Cell Carcinoma. All 8 cases of keratinizing Squamous cell carcinoma were seen in old age group (>60 yrs). However the cases of Nonkeratinizing nasopharyngealcarcinoma showed a bimodal age distribution.

\section{EBV association}

Out of 92 cases of Non keratinizing Carcinoma, 75 cases were positive for EBV, while all cases of keratinizing Squamous cell carcinoma were negative for EBV (Table 2 \& Figure 5). Non keratinizing type of Nasopharyngeal carcinoma has a strong association with EBV and was calculated by using Chi-square test (p-value $<0.005)$.

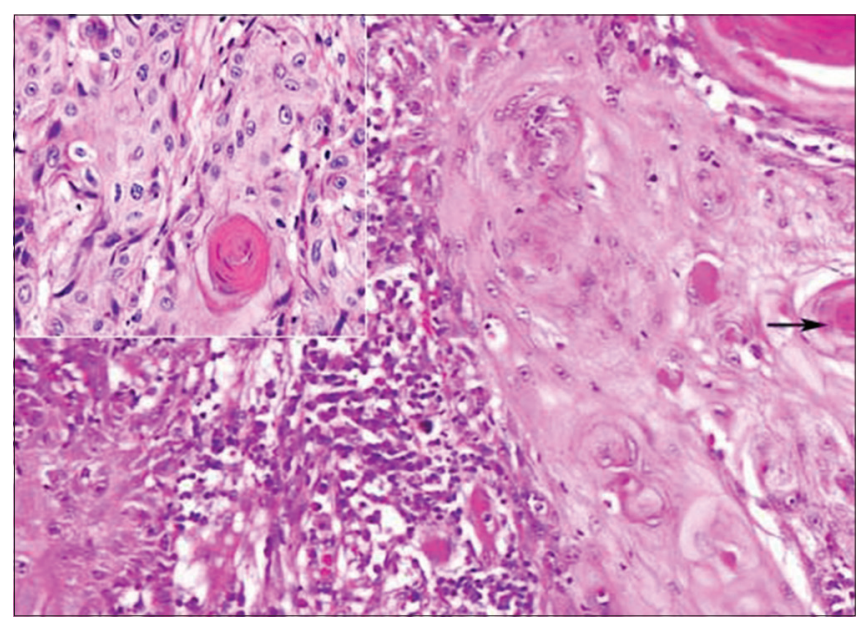

Figure 3: Keratinizing squamous cell carcinoma of the nasopharynx showing keratin pearl formation $\rightarrow(20 \mathrm{X})$ and the inset shows tumor at higher magnification (40X)

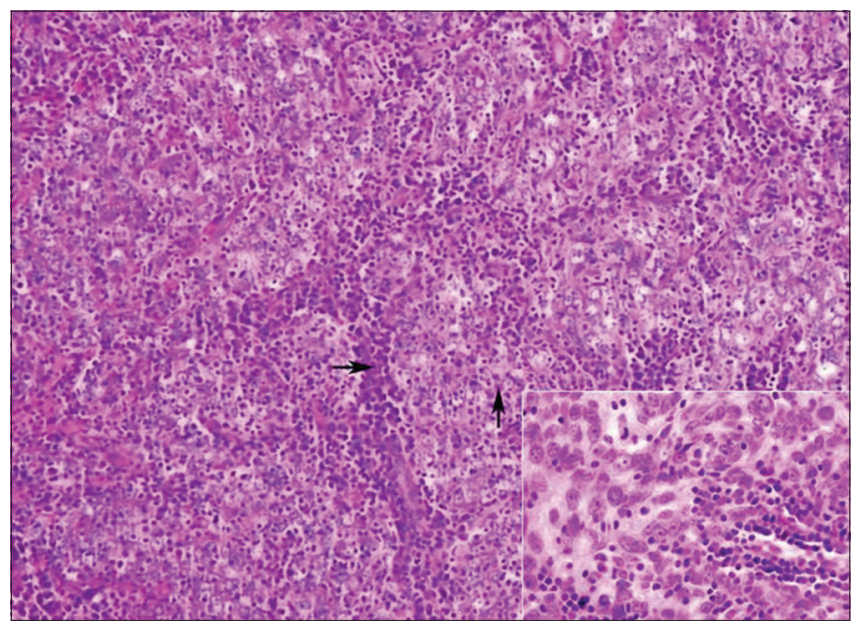

Figure 4: Non-Keratinizing carcinoma showing large tumor cells $\uparrow$ and an inflammatory infiltrate rich stroma $\rightarrow(20 \mathrm{X})$ and the inset shows tumor cells at higher magnification (40x)

\section{DISCUSSION}

Nasopharyngeal carcinoma, the most common type of nasopharyngeal tumor being remarkable for the striking geographic differences in its incidence as well as in its association with the Epstein-Barr virus. ${ }^{3}$ It is a rare tumor in many parts of the world, with an incidence well under 1 per 100,000 persons-years. ${ }^{9}$ In contrast, NPC is endemic in southern China, including Hong Kong and Taiwan where the incidence may reach 25 cases per 100,000 per year. Intermediate risk regions include Southeast Asia, the Mediterranean basin (North Africa and the Middle East), and the Arctic. ${ }^{10}$ In Hong Kong, nasopharyngeal carcinoma accounts for $18 \%$ of all malignant neoplasms, as opposed to approximately $2 \%$ in the United States. All types of nasopharyngeal carcinoma show male predominance. ${ }^{11}$ Squamous cell carcinomas are rare in childhood. In contrast undifferentiated carcinoma shows a distinct bimodal age 


\begin{tabular}{|c|c|c|}
\hline & $\begin{array}{l}\text { Non-keratinizing } \\
\text { carcinoma }\end{array}$ & $\begin{array}{l}\text { Keratinizing squamous } \\
\text { cell carcinoma }\end{array}$ \\
\hline EBV positive cases & $75(81.5 \%)$ & 0 \\
\hline EBV negative cases & $17(18.4)$ & 8 \\
\hline Total & 92 & 8 \\
\hline
\end{tabular}

distribution, with peaks in the second and third decade and a second peak in sixth decade. This study also demonstrates a male predominance. The male: female ratio was found to be 3:1. The age range was 13-78 years with an average age of 42 years. Majority of the cases fell in the group of Non-keratinizing carcinoma with many cases initially presenting with metastases rather than the primary site.

Several studies using different methods have also confirmed EBV association with the nasopharyngeal carcinoma. Non-keratinizing Nasopharyngeal carcinoma has a strong association with the EBV as compared to the keratinizing squamous cell carcinoma. Infrequent association of keratinizing squamous cell carcinoma with EBV may also indicate a different carcinogenesis involved in this sub-type of tumor. ${ }^{12}$

According to a study carried out in Taiwanese population, it was also shown that serologic markers of EBV infection can appear long before the development of nasopharyngeal carcinoma and measurement of these antibodies may also be helpful in the early detection of the cancer. ${ }^{13}$

Non-keratinizing type of nasopharyngeal carcinoma is the commonest type in the regions of world where nasopharyngeal carcinoma is prevalent and also has a strong association with EBV. In this regard, patients may also benefit from the emerging vaccinations against EBV to prevent them developing Nasopharyngeal carcinoma (and other malignancies associated with EBV) later. Several trials are now underway for the development of successful vaccination against primary infection of EBV..$^{14,15}$ In developing countries and lower socioeconomic groups primary infection typically occurs in the first few years of life. In contrast, in western communities and higher socioeconomics groups primary infection is delayed until adolescence in larger percentage of people. ${ }^{16}$

The poor prognosis for patients with nasopharyngeal carcinoma is principally due to its advanced stage at the time of diagnosis. ${ }^{17}$ Also in our study, in good number of cases the disease has spread beyond the primary site at the time of presentation. For the tumors remain confined to the nasopharynx, the 5 year survival is approximately $75 \%$. The presenting stage is one of the most important prognostic factors affecting the survival for patients with

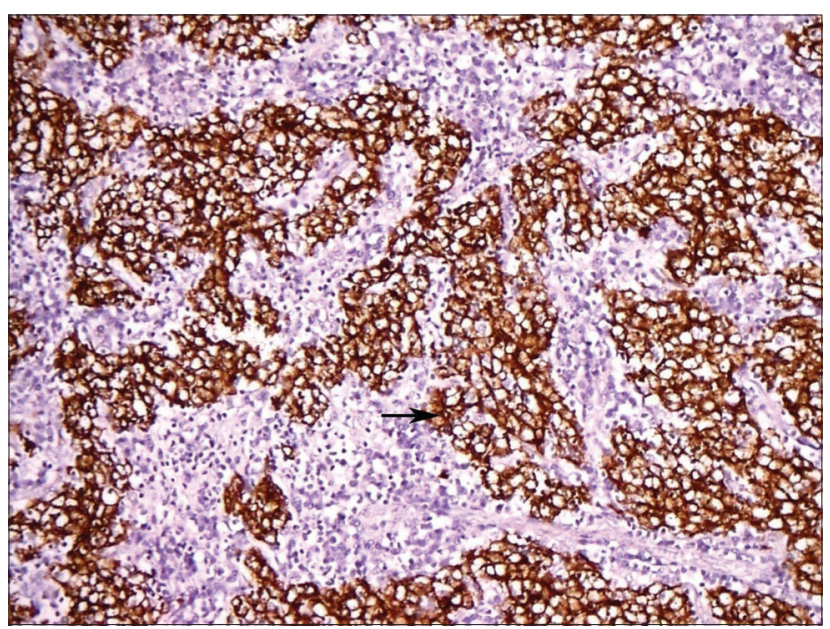

Figure 5: Tumor cells showing positivity for EBV-LMP1 $(\rightarrow 20 \mathrm{X})$

nasopharyngeal carcinoma. ${ }^{11} \mathrm{NPC}$ at an early stage can be cured by radical radiotherapy, there is a high recurrence rate in patients with advanced NPC.

LMP 1 is an integral transmembrane EBV protein and is thought to be a key modulator in the pathogenesis of nasopharyngeal carcinoma. However the prognostic impact of LMP-1 is still unclear but according to few studies, expression of LMP-1 seems to worsen the prognosis of nasopharyngeal carcinoma. ${ }^{18,19}$ In another study carried out by Sarac et al it has been concluded that cervical lymph node metastases and cranial nerve involvement are the only variables significantly affecting patient's survival and the expression of $\mathrm{Bcl} 2$ and LMP 1 was strongly correlated with cervical lymph node metastases. ${ }^{20}$ This also provides an insight for the development of targeted therapy against LMP-1 to benefit this patients cohort. ${ }^{21}$

The presence of high circulating levels of EBV DNA has a good correlation with the prognosis of NPC. In a study by Chan et al, post treatment EBV DNA levels of $>500$ copies $/ \mathrm{ml}$ was significantly associated with the poorest outcome, on the contrary patients with post treatment levels of $<500$ copies $/ \mathrm{ml} \mathrm{had} \mathrm{a} \mathrm{better} \mathrm{prognosis.}{ }^{22}$ In another study by Ferrari et al, $97 \%$ of patient had pretreatment levels of $>350$ copies $/ \mathrm{ml}$ that significantly correlated with tumor stage (lower values in stage IIb as compared in stages III-IV). ${ }^{23}$

Speculations about the role of immunotherapy and possible prognostic effect of EBV infection on the course of nasopharyngeal carcinoma are tempting. To prove either a possible adverse effect by the oncogenic capacity of LMP-1 or a putative protective effect due to stimulation of a specific immune response against EBV infection, large series of patients with comparable clinical criteria and standardized therapeutic regimens need to be looked at in our population. 


\section{REFERENCES}

1. Fatusi $O$, Akinpelu $O$ and Amusa $Y$. Challenges of managing Nasopharyngeal carcinoma in a developing country. J Natl Med Assoc 2007; 98(5):758-764.

2. Fribrog J, Wohlfahrt J, Koch A, Storm H, R.Olsen O and Melbye $M$. Cancer susceptibility in nasopharyngeal carcinoma families. Clin Cancer Res 2005; 65(18):8567-8572.

3. Chan JKC, Pilch BZ, Kuo TT, Weing BM, Lee AWM. Tumors of the nasopharynx. In: Barnes L, Eveson JW, Reichart P, Sidransky $D$ editors. Pathology \& Genetics head and Neck tumors. Lyon; France: IARC Press, 2003.p.81-106.

4. Chan ATC, Teo PMI and Johnson PJ. Nasopharyngeal Carcinoma. Ann Oncol 2002; 13(7):1007-1015.

5. Bar-Sela G, Kuten A, Minkov I, Gov-Ari E and Ben-Izhak O. Prevalence and relevance of EBV latency in Nasopharyngeal Carcinoma in Israel. J Clin Pathol 2004; 57(3):290-293.

6. Matthew $P$ and Thompson Kurzrock R. Epstein Barr Virus and cancer. Clin Cancer Res 2004; 10:803-821.

7. Dietz A, Logothetis CA, Helbig M, Flechtenmacher C, Rudat V, Dollner R, et al. Prognostic impact of EBV related LMP 1, histological types and environmental factors in nasopharyngeal carcinoma in German population. Oncology 2004; 27(4):345-350.

8. Krishna SM, James S, Kattoor J and Balaram P. Serum EBVDNA as a biomarker in primary Nasopharyngeal carcinoma of Indian origin. Jpn J Clin Oncol 2004; 34(6):307-311.

9. Yu MC and Yuan JM. Epidemiology of Nasopharyngeal Carcinoma. Semin Cancer Biol 2002; 12(6):421-429.

10. Chan ET and Adami HO. The enigmatic epidemiology of nasopharyngeal carcinoma. Cancer Epidemiol Biomarkers Prev 2006; 15(10):1765-1777.

11. Shanmugaratnam K, Chan SH, de the G, Goh JE, Khor TH, Simons MJ, et al. Histopathology of Nasopharyngeal carcinoma: correlations with epidemiology, survival rates and other biological characteristics. Cancer 1979; 44(3):1029-1044.

12. Hording $U$, Nielsen HW, Albeck $H$ and Daugaard $S$. Nasopharyngeal Cacinoma: histopathological types and association with Epstein-Barr virus. Eur J Cancer 1993;
29(2):137-139.

13. Chien YC, Chen JY, Liu MY, Yang HI, Hsu MM, Chen CJ, et al. Serological markers of Epstein-Barr virus infection and nasopharyngeal carcinoma in Taiwanese men. N Eng J Med 2001; 345(26): 1877-1882.

14. Cohen JI, Mocarski ES, Raab-TRaub N, Corey L and Nabel GJ. The need and challenges for development of an Epstein Barr virus vaccine. Vaccine 2013; 31(2):194-196.

15. Ruiss R, Jochum S, Wanner G, Reisbach G, Hammerschmidt W and Zeilder R. A virus like particle based Epstein Barr virus vaccine. J virol 2011; 85(24):13105-13113.

16. Moss DJ, Suhrbier A and Elliott SL. Candidate vaccines for Epstein Bar virus: several promising approaches for vaccines against primary infection. Br med J1998; 317(7156):423-424.

17. Suzina SAH and Hamzah M. Clinical presentation of patients with nasopharyngeal carcinoma. Med J Malaysia 2003; 58(4):539-545.

18. Plaza G, Fogue L, Martinez San Millan J, Martinez Vidal A and Bellas C. Diagnostic evaluation of nasopharyngeal carcinoma: role of Epstein-Barr virus. Ann Otolaryngol Am 2002; 29(1):71-91.

19. Guo Q, Tham IWK, Lin S, Su Y, Chen Z, Lin J, et al. Prognostic significance of pre-treatment latent membrane protein 1 from nasopharyngeal swabs for stage III-IVA nasopharyngeal carcinoma. Head neck oncol 2012;4(4):81.

20. Sarac C, Akyol MU, Kanbur B, Poyraz A, Akyol G, Yilmaz T, et al. $\mathrm{Bcl} 2$ and LMP1 expression in nasopharyngeal carcinomas. Am J Otolaryngol 2001; 22(6):377-382.

21. Chen R, Zhang D, Mao Y, Zhu J, Ming H, Wen J, et al. A human Fab based immunoconjugate specific for the LMP 1 extracellular domain inhibits nasopharyngeal carcinoma growth in vitro and in vivo. Mol Cancer Ther 2012; 11(3):594-603.

22. Chan AT, Lo YM, Zee B, Chan LY, Ma BB, Leung SF, et al. Plasma Epstein-Barr virus DNA and residual disease after radiotherapy for undifferentiated nasopharyngeal carcinoma. J Natl Cancer Inst 2002; 94(21):1614-1619.

23. Ferrari D, Codeca C, Bertuzzi C, Broggio F, Crepaldi F, Luciani $A$, et al. Role of plasma EBV DNA levels in predicting recurrence of nasopharyngeal carcinoma in a western population. BMC cancer 2012; 12(208):1-7.

\section{Authors Contribution:}

BU \& RA - designed the study, collected \& analyzed the data; BU - drafted the manuscript; RA - reviewed the manuscript. 